\title{
Improved house mouse control in the field with a higher dose zinc phosphide bait
}

\author{
Wendy A. Ruscoe ${ }^{1,4}$, Peter R. Brown ${ }^{1}$, Lyn A. Hinds ${ }^{1}$, Steve Henry ${ }^{1}$, Nikki Van de Weyer ${ }^{1,2}$, Freya \\ Robinson $^{1}$, Kevin $\mathrm{Oh}^{1,2}$, Richard P. Duncan ${ }^{1,3}$ \\ ${ }^{1}$ CSIRO Health \& Biosecurity, GPO Box 1700, Canberra, ACT 2601, Australia \\ ${ }^{2}$ Applied BioSciences, Macquarie University, Sydney, NSW, Australia \\ ${ }^{3}$ Centre for Conservation Ecology and Genomics, Institute for Applied Ecology, University of Canberra, \\ ACT, Australia \\ ${ }^{4}$ Corresponding author: Wendy.Ruscoe@csiro.au
}

\begin{abstract}
Recent studies have shown the sensitivity of wild house mice to $\mathrm{ZnP}$ poison in Australia is significantly lower than previously assumed which may account for the reported variability in efficacy of $\mathrm{ZnP}$ baits used for broadacre control of house mice in grain growing regions. Under laboratory conditions $\mathrm{ZnP}$ coated grains coated with a new higher dose $(50 \mathrm{~g} \mathrm{ZnP/kg}$ grain) were readily consumed but its efficacy under natural field has not been tested. To test if the newly derived ZnP50 (50 g ZnP/kg grain) was more effective under field conditions than the currently registered $\mathrm{ZnP} 25$ (25 g ZnP/kg grain) in reducing populations of house mice during a mouse population irruption.
\end{abstract}

We used a Before-After-Control-Impact (BACI) design analysing population size estimate changes in a replicated field trial. We assessed mouse abundance changes after baiting in recently sown paddocks with either ZnP50 ( $\mathrm{n}=3$ ) or $\mathrm{ZnP25}(\mathrm{n}=3)$ compared to unbaited Control sites $(\mathrm{n}=3)$ grain. Our results showed a median of $>85 \%$ reduction in mouse numbers as a result of the ZnP50 Treatment. Using simulation modelling we show that under similar circumstances, the use of the ZnP50 formulation will deliver $>80 \%$ reduction in population size most $(>90 \%)$ of the time. In contrast, the current registered bait ( $\mathrm{ZnP} 25)$ achieved approximately $70 \%$ reduction and produced highly variable results. We would only be confident of getting an $80 \%$ reduction in population size, $20 \%$ of the time using the currently registered $\mathrm{ZnP} 25$ bait under similar field conditions.

Consistent with laboratory studies, this study demonstrates the far higher probability of achieving a high kill rate with the new ZnP50 bait compared to the currently registered formulation ( $\mathrm{ZnP} 25)$. By using the new ZnP50 bait, farmers are far more likely to get good kill rates thereby reducing the need for repeated baiting (which is costly and generally ineffective at protecting newly sown crops) or use higher application rates (3-5 kg/ha) that exceed those permitted by labels. This will result in minimising the cost of control to farmers and reduce the number of toxic grains being spread to control mice.

Keywords: Mus musculus, ZnP, toxin, bait, pest control, efficacy, broadacre cereal farms, rodent

\section{Introduction}

Wild house mice (Mus musculus) in Australia undergo periodic plagues over vast areas of agricultural land with densities exceeding 800 mice/ha, resulting in serious damage to agricultural crops (Singleton 
et al. 2005). Records of mouse plagues in New South Wales (Saunders and Giles 1977), Victoria and South Australia (Mutze 1989), coupled with reports from Queensland (Caughley et al. 1994; Pople et al. 2013), and to a lesser extent Western Australia (Chapman 1981), indicate that, on average, a plague occurs in at least one state in Australia every four years, most commonly in the cereal growing regions (Singleton et al. 2005). The 1993 mouse plague that affected South Australia and Victoria was estimated to have caused AU\$64.5M (in 1993) worth of damage to cereal crops (Caughley et al. 1994), with offfarm costs (reflecting mouse damage to infrastructure, produce, and the cost of cleaning up) conservatively estimated to be AU\$1M (Caughley et al. 1994). The 2011 mouse plague reportedly caused over \$200M in crop damage alone (S. Humphrys, National Mouse Management Working Group, in Hinds et al. (2014)), and the 2021 plague was of similar magnitude and extending into Western Australia as of January 2022 (G. Martin, Crop Protection Manager, GRDC, pers. comm).

Farmers attempt to control mouse populations in their fields by applying the acute rodenticide zinc phosphide. Registered rodenticide baits for in-field application in Australia contain 25 grams of zinc phosphide $\left(\mathrm{Zn}_{3} \mathrm{P}_{2}\right.$, hereafter referred to as $\left.\mathrm{ZnP}\right)$ per kilogram wheat bait as a surface coating ( $25 \mathrm{~g} \mathrm{ZnP/kg}$ grain, hereafter referred to as $\mathrm{ZnP} 25 ; 2.5 \% \mathrm{w} / \mathrm{w}$ ). At this dose rate, a single grain was assumed to be lethal to a $20 \mathrm{~g}$ mouse (Staples et al. 2003). The current label application rate is $1 \mathrm{~kg}$ bait/ha which equates to approximately $2-3$ grains $/ \mathrm{m}^{2}$ or about 25,000 toxin-coated grains/ha. This rate should be sufficient for effective population control.

$\mathrm{ZnP}$ is a fast acting, acute (single dose) toxic agent used for vertebrate pest control in multiple countries, including Australia, India, China, various countries in Southeast Asia, parts of Europe and the USA, with its use as a rodenticide beginning as early as 1911 in Italy (Tickes 1985). It is used around the world due to its relatively good safety record, low cost, and reasonably high efficacy against a range of target rodent species (Sugihara et al. 1995). While several effective anticoagulant rodenticides are available for the control of rodents in industrial and domestic situations, they are not suitable for the control of broadscale rodent infestations in crops due primarily to the potential for bioaccumulation in the food chain (see Lohr and Davis (2018) for review). When ingested, ZnP reacts immediately with stomach acids to release highly toxic phosphine gas that is quickly absorbed into the bloodstream to affect the lungs, liver, kidneys, heart and central nervous system (Guale et al. 1994). Death usually results from heart and kidney failure within 24 hours but can be up to 112 hours (Henry et al. 2021; Hinds et al. 2021). One benefit of using acute poisons is that secondary poisoning risks to predators and scavengers from $\mathrm{ZnP}$ exposure are low especially when compared to other rodenticides (anticoagulants). As $\mathrm{ZnP}$ and phosphine do not bioaccumulate in the tissue of target animals, secondary risk is related to only the consumption of undigested bait in the gastro-intestinal tract of target animals (Tkadlec and Rychnovsky 1990; Sterner and Mauldin 1995). Zinc phosphide is a dull grey-black colour that is unattractive to birds. It also causes an emetic (vomiting) response in most animals (but not rodents), reducing non-target fatalities (McLeod and Saunders 2013). 

$\mathrm{ZnP}$ is the only rodenticide registered for in-crop use in Australia (APVMA 2000). Its application has been a key management tool for grain-growers for many years (Mutze 1993; Brown et al. 1997; Brown et al. 2002; Mutze and Sinclair 2004) and it is easy to apply by aerial or ground methods. In Australia, $\mathrm{ZnP}$ can reduce mouse populations by up to 95\% (Brown et al. 2002; Mutze and Sinclair 2004), but its efficacy can be variable (Caughley et al. 1998b; Brown et al. 2002). For example, mouse numbers in the southern Australian cereal growing area were high in 2016 (Ruscoe et al. 2022) but multiple anecdotal reports from farmers claimed that baiting at the prescribed rate had variable success in controlling mouse numbers (S Henry and PR Brown pers. comm.). Previously this variability in kill rates has been attributed to the presence of alternative food sources, such as mature crops containing seed heads or post-harvest spilled grain. However, a recent study investigating how alternative food affected bait-take by mice found that mice ingesting bait at rates far higher than the published lethal dose were surviving and becoming averse to toxic grains (Henry et al. 2021). This led to a reexamination of the median lethal dose rate $\left(\mathrm{LD}_{50}\right)$ using oral gavage trials on both Australian wild caught and a laboratory strain of mice. These laboratory trials found that the $\mathrm{LD}_{50}$ was $72-79 \mathrm{mg} \mathrm{ZnP} / \mathrm{kg}$ body weight (BW) (Hinds et al. 2021), a value significantly higher than the $32.7 \mathrm{mg} \mathrm{ZnP/kg} \mathrm{BW}$ previously reported by $\mathrm{Li}$ and Marsh (1988), which was the value on which the currently registered bait is formulated. Given the results of Hinds et al. (2021) a new higher strength bait was developed based on a lethal dose rate ( $\mathrm{LD}_{90}: 110 \mathrm{mg} \mathrm{ZnP/kg} \mathrm{BW}$ ) which equates to an application rate of $50 \mathrm{~g} \mathrm{ZnP/kg}$ wheat bait (hereafter referred to as ZnP50), whereby each wheat grain is coated with $\sim 2 \mathrm{mg} \mathrm{ZnP}\left(\mathrm{LD}_{90}\right.$ dose for $15 \mathrm{~g}$ mouse). Laboratory feeding trials showed that mice readily consumed this new ZnP50 bait and mortality was high (94\%) in the absence of alternative food (Hinds et al. 2021). This ZnP50 bait was granted an emergency permit for use during the 2021 eastern Australia mouse plague (Australian Pesticide and Veterinary Medicines Authority (APVMA) permit - PER90799, May 2021).

The purpose of this study was to evaluate the performance of the new ZnP50 bait compared to currently registered ZnP25 baits in cropping fields as farmers were baiting their paddocks during a mouse outbreak. We used a randomised experiment to determine if the new bait could deliver better population reductions of house mice than the currently registered bait ( $\mathrm{ZnP} 25)$. We were able to test the new bait after the regulatory authority, AVPMA, approved an emergency permit for the use of ZnP50 during the 2021 mouse plague in eastern Australia. We used a Before-After-Control-Impact (BACI) design to compare changes in the density of mouse populations subject to three treatments: Treatment 1 - baiting using ZnP25, Treatment 2 - baiting using ZnP50, and Untreated Controls.

\section{Materials and methods}

Study design 
We selected nine sites (paddocks) in newly sown wheat or canola crops (generally cultivars of Triticum aestivum, Brassica napus, L. or Brassica rapa L.) around Parkes, central NSW, Australia $\left(33.1373^{\circ}\right.$ S, $148.1747^{\circ} \mathrm{E}$ ) in May 2021. On all sites, farmers had rolled and burnt stubble in efforts to reduce mouse numbers in preparation for sowing. Our trial commenced 4 weeks after crop sowing, meaning the sites had very little ground cover. At the time of our trial, eastern Australia was experiencing high to 'plague' numbers of house mice in cropping landscapes and nearby towns. While many farmers were undertaking mouse control using $\mathrm{ZnP}$ baits to protect newly sown crops from mouse damage, we selected sites where no in-crop ZnP baiting had occurred in the current year or for at least 10 years prior (the last time there was a widespread mouse outbreak in this region of eastern Australia).

\section{Experimental sites}

Each experimental site was approximately 16 ha in size, with sites clustered in two 'Blocks' located about $20 \mathrm{~km}$ apart, with three sites in Block 1 and six sites in Block 2. Sites in each block were within $2 \mathrm{~km}$ of each other. Two of the sites were slightly smaller than the others ( 11 ha) and were designated Control sites (one in each Block). The remaining sites were randomly allocated to experimental treatments such that the three sites at Block 1 comprised $1 \times$ Control, $1 \times \mathrm{ZnP} 25$, and $1 \times \mathrm{ZnP50}$ Treatment, and the six sites at Block 2 comprised 2 x Control, 2 x ZnP25, and 2 x ZnP50 Treatments. To census mouse populations, we located trapping grids as centrally as possible within each site. Each trapping grid covered 0.64 ha, meaning there was a sufficient buffer area around each grid where mice had been controlled to minimise immigration into the trapping grid following baiting. Previous trapping studies of house mice in Australia have estimated median home ranges of 0.119-0.199 ha during the non-breeding season (Krebs et al. 1995; Chambers et al. 2000).

\section{Experimental Treatments}

There were three treatments each with three replicates in this experiment, for a total of nine sites. The treatments were:

1. Untreated Control: an untreated control where no bait was applied,

2. Treatment $\mathbf{Z n P 2 5}$ : commercially available $\mathrm{ZnP} 25$ bait ( $25 \mathrm{~g} \mathrm{ZnP} / \mathrm{kg}$ bait), equating to approximately $1 \mathrm{mg} \mathrm{ZnP}$ per grain, applied at $1 \mathrm{~kg}$ bait/ha (label rate)

3. Treatment ZnP50: newly derived ZnP50 bait (50 g ZnP/kg bait), equating to approximately 2 mg ZnP per grain, applied at $1 \mathrm{~kg}$ bait/ha under an APVMA Emergency Permit (APVMA permit - PER90799, May 2021).

Mouse baits were sourced from a commercial bait manufacturer as toxin-coated sterilised wheat grain in sealed metal drums (Last Supper Supreme Zinc Phosphide (Broadacre) Mouse Bait, Wilhelm Rural 
Pty Ltd) in either the $25 \mathrm{~g}$ zinc phosphide/kg (ZnP25) or $50 \mathrm{~g}$ zinc phosphide/kg (ZnP50) active ingredient baits.

Toxic baits were applied to each treatment site using a Sharman Bait Spreader (MD \& LA Sharman Pty Ltd) mounted on the back of a four-wheel-drive farm utility vehicle. The same vehicle, driver and bait spreader were used on all sites for consistency, with the spreader emptied of residual bait and refilled between each site. All sites were baited on the same day, with $\mathrm{ZnP} 25$ sites baited first, followed by ZnP50 sites. The spreader was calibrated according to manufacturer instructions to deliver $1 \mathrm{~kg}$ toxic grain per ha as it was driven over the paddocks at a set speed in parallel lines $15 \mathrm{~m}$ apart to give complete coverage of the area.

\section{Population monitoring}

A Pre-treatment survey of mouse populations at all sites was carried out from 29 May-3 June 2021 (four nights trapping). Treatments were applied on 5 June 2021 and Post-treatment surveys were carried out three days later from 8-13 June 2021 (five trapping nights). Trapping was extended to 5 nights Posttreatment as the first 2 nights were wet (15- and 22-mm rain) which may affect capture probabilities and hence population estimates, especially when few animals were expected to be trapped on treated grids. Mouse populations were surveyed using capture-mark-recapture (CMR) techniques, based on livecapture data from traps laid out in a single grid within each of the nine sites. Sixty-four live-capture Longworth box traps (Longworth Scientific, Abingdon, UK) were placed on an 8 × 8 grid at 10-m spacing. Traps were baited with wheat grains and provided with bonded polyester fibre (Dacron) for bedding. Traps were checked each morning and re-set each afternoon during a trapping session. All animals were individually marked (Biomark RFID PitTags), and their weight, body length, sex and breeding condition were recorded before being released at the point of capture.

\section{Population size estimation}

We analysed the capture-mark-recapture (CMR) data to estimate the numbers of mice on each trapping grid at each survey, assuming that populations were closed during each trapping survey. We used the method described in Royle et al. (2009), which allowed us to model heterogeneity in detection probabilities implemented in a Bayesian framework via data augmentation (see Supporting Information for details). The outcome of the capture-mark-recapture analysis was an estimate of population size on each grid at each survey, expressed as a posterior distribution specifying the probability that the number of individuals took a particular value, having accounted for variation in capture probability across grids, nights, and among individuals. From this we derived the best estimate of population size on each grid at each survey as the mean of the posterior distribution, along with two measures of uncertainty: the 
variance and 95\% credible intervals (CIs) of the posterior distribution. A 95\% credible interval defines the bounds within which we are $95 \%$ confident that a parameter value lies. We converted numbers of mice to density by dividing the estimated population size by the grid size $(80 \times 80 \mathrm{~m}$ which includes a $5 \mathrm{~m}$ buffer around the outer traps $=0.64 \mathrm{ha}$ ).

\section{Before-After Control-Impact analysis}

We used a replicated Before-After-Control-Impact (BACI) design comprising population size estimates taken before and after implementation of the treatments. To test treatment efficacy, we modelled logtransformed estimates of mouse population size as a function of survey (Pre-treatment vs Posttreatment), experimental treatment (Control, ZnP25, ZnP50) and their interaction. We incorporated the uncertainty in mouse population size estimates into the analysis by modelling the (log transformed) mean number of mice at the $j$ th site during the $k$ th survey $\left(N_{j k}\right)$ as drawn from a normal distribution with variance that was a function of within-site-survey variation (the uncertainty in estimated population size, $s_{j k}^{2}$, which was the variance in $\log \left(N_{j k}\right)$ derived from the posterior distribution) and between-sitesurvey variation (unexplained random variation, $\sigma^{2}$, estimated in model fitting) as follows (Eqn 1):

$$
\log \left(N_{j k}\right) \sim \operatorname{Normal}\left(\beta_{0}+\beta_{1} s_{\text {Post }}+\beta_{2} t_{25}+\beta_{3} t_{50}+\beta_{4} i_{\text {Post_25 }}+\beta_{5} i_{\text {Post_50 }}+\beta_{6} b_{2}, \sqrt{\sigma^{2}+s_{j k}^{2}}\right)
$$

Where $s_{\text {Post }}$ is a dummy variable having value 1 for sites measured post-survey and 0 otherwise, $t_{25}$ and $t_{50}$ are dummy variables having value 1 for the $\mathrm{ZnP} 25$ and ZnP50 Treatments, respectively, and 0 otherwise, $i_{\text {Post_25 }}$ and $i_{\text {Post_50 }}$ are dummy variables for interaction terms having value 1 for the post$\mathrm{ZnP} 25$ and post-ZnP50 surveys, respectively, and 0 otherwise, and $b_{2}$ is a dummy variable coding for Block 1 (0) and Block 2 (1). The $\beta$ s are parameters estimated in model fitting. We fitted the above model in a Bayesian framework using Markov Chain Monte Carlo (MCMC) methods as implemented in the JAGS software (Plummer 2003) using the package jagsUI (Kellner 2015) called from R v. 4.0.1 (R Core Team 2020). The model was run with three chains for 10,000 iterations following a burn-in of 5,000 iterations, which was sufficient to achieve convergence as judged by the Gelman-Rubin statistic (Gelman and Rubin 1992).

In this analysis, most attention focuses on parameters $\beta_{4}$ and $\beta_{5}$, which estimate the Post-treatment difference in mouse population size between the Control and the ZnP25 and ZnP50 Treatments, respectively, having accounted for Pre- and Post-treatment changes at the Control site $\left(\beta_{1}\right)$, any overall difference in population size between the Control and ZnP Treatments $\left(\beta_{2}\right.$ and $\left.\beta_{3}\right)$, and any overall difference in population size between blocks $\left(\beta_{6}\right)$. Negative parameter estimates for $\beta_{4}$ and $\beta_{5}$ would 
indicate that application of the $\mathrm{ZnP}$ baiting treatments resulted in lower Post-treatment mouse populations relative to the Control sites.

Because we modelled $N_{j k}$ on the log scale, transforming the parameters to $e^{\beta_{4}}$ or $e^{\beta_{5}}$ estimates the ratio of Control (C) to Treatment (T) population size Post-treatment, e.g., C/T. We can then estimate the proportional reduction in population size at Treatment sites relative to Control sites as $(\mathrm{C}-\mathrm{T}) / \mathrm{T}$, which, for the $\mathrm{ZnP} 25$ Treatment, is given by $e^{\beta_{4}}-1$. We used this proportional reduction in population size for each Treatment relative to Control sites as a measure of treatment efficacy.

\section{Bait toxicity testing}

A sample of 10 toxic grains was taken from each drum used for each treatment site as the bait spreader was being loaded. These $\mathrm{ZnP}$-coated grains were individually analysed to confirm the expected coating rate of approximately 1 and $2 \mathrm{mg} \mathrm{ZnP}$ per grain for the ZnP25 and ZnP50 mixed rates respectively. Analysis was undertaken by ACS Laboratories (Australia) (37 Stubbs St, Kensington, Victoria, 3031), a commercial, independent analytical service provider accredited by the National Association of Testing Authorities (NATA), Australia (NATA Accreditation No 16973). Grains coated with ZnP were individually analysed by microwave digestion followed by inductively coupled plasma optical emission spectroscopy (ICP-OES). Each grain was weighed directly into a Teflon digestion tube to which $5 \mathrm{ml}$ of concentrated nitric acid and $1 \mathrm{ml}$ of $30 \%$ hydrogen peroxide were added. Each digestion tube was then microwaved for 65 minutes using a temperature gradient from $0-200^{\circ} \mathrm{C}$ in a Milestone Connect Ethos Lean Compact Microwave Digestor. Once cooled the contents of the digestion tube were diluted to $50 \mathrm{ml}$ in deionised water, followed by a further 10-fold dilution in deionised water for ICP analysis using an Agilent 5110 ICP-OES (Dual View). The operating conditions for the instrument were: 1.20 kW RF power; plasma 15.0 L/min; auxiliary 1.50 L/min; AVS7 sample injection system; injection pump rate $15.7 \mathrm{ml} / \mathrm{min}$; detection - intensity, Zn $206.2 \mathrm{~nm} / \mathrm{c} / \mathrm{s}$.

\section{Results}

Population size estimation

We trapped 1651 individuals over the two-week study (1261 in the Pre-treatment survey and 390 in the Post-treatment survey). Mouse body weight averaged $12.8 \mathrm{~g}$ over all grids and surveys, indicating a predominantly young adult population. Very few younger animals ( $<10 \mathrm{~g})$ were trapped, and no pregnant/lactating females or scrotal males were observed. Estimates of mouse population size from the capture-mark-recapture analyses from each survey on each grid are shown in Table 1. Pre-treatment mouse numbers were estimated at between 300 - 500 mice per ha 
256 Population size was uniformly higher on Block 1 sites and these sites also experienced greater 257 population reductions Pre- to Post-treatment including on the Control site (Table 1, Fig. 1). Figure 1 258 shows CMR estimates of population density $\left(\mathrm{ha}^{-1}\right)$ for each site in each treatment by survey. On average, 259 the number of mice present on the Control sites decreased between the two surveys. However, larger 260 population reductions Pre- to Post-treatment were seen on the treated sites, particularly the ZnP50 sites 261 (Table 1) in number of individuals caught, CMR population estimates and trap success. The number of 262 individuals caught, and trap success is presented (Table 1) for comparison with previous Australian baiting studies.

\section{Before-After Control-Impact analysis}

266

267

268

269

270

271

272

The BACI analysis used to evaluate treatment efficacy (Eqn 1) estimates the reductions in populations sizes as a function of survey (Pre-treatment vs Post-treatment), experimental Treatment (Control, $\mathrm{ZnP25}, \mathrm{ZnP50}$ ) and their interaction and incorporating uncertainty in mouse population size estimates. The posterior distribution of the proportional reduction in population size for Treatment relative to Control sites (treatment efficacy) estimated from the BACI analysis is shown in Fig. 2. Using the ZnP25 bait, the median expected reduction in population size was approximately $70 \%$, with a $50 \%$ probability of observing a population reduction of between 58-78\%. In contrast, the median expected population reduction associated with using the $\mathrm{ZnP50}$ bait was approximately $90 \%$, with a $50 \%$ probability of a population reduction between $84-92 \%$.

Assuming at least an $80 \%$ reduction in population size was the desired outcome of a baiting program, the new ZnP50 bait had a 95\% probability of achieving that outcome or better, while the currently registered $\mathrm{ZnP} 25$ bait had a 20\% probability of achieving that outcome or better (Fig. 3).

\section{Bait testing}

Independent analysis $\mathrm{ZnP}$-coated grains confirmed the expected average coating rate per grain. On average, individual grains of the $\mathrm{ZnP} 25$ batch ( $25 \mathrm{~g} \mathrm{ZnP} / \mathrm{kg}$ grain) were coated with $0.97 \pm 0.06 \mathrm{mg} \mathrm{ZnP}$ (mean \pm se; range: $0.48-1.66 \mathrm{mg} ; \mathrm{n}=30$ ), those from the $\mathrm{ZnP} 50$ batch (50 $\mathrm{g} \mathrm{ZnP} / \mathrm{kg}$ grain) were coated with $1.83 \pm 0.13 \mathrm{ZnP}$ (mean \pm se; range: $0.81-4.0 \mathrm{mg}$; $\mathrm{n}=30$ ). 


\section{Discussion}

This study showed that the new ZnP50 bait (50 g ZnP/kg grain) performed well in a field trial. The proportional reduction in mouse population size Pre- to Post-treatment relative to Control sites (treatment efficacy) for the $\mathrm{ZnP50}$ bait had a median value of $>85 \%$. Accounting for variation among experimental sites and uncertainties in capture-mark-recapture population estimates, we estimate that the $\mathrm{ZnP50}$ bait delivered a $>80 \%$ reduction in mouse population size with $>90 \%$ certainty. In contrast, the outcome of using the currently registered bait ( $\mathrm{ZnP} 25)$ was far less certain. We estimated a median reduction in population size of $<75 \%$, and that this bait delivered a $>80 \%$ reduction in population size with only $20 \%$ certainty.

Similarly variable kill rates using the currently registered $\mathrm{ZnP} 25$ have been reported: Brown et al. (2002) surveyed mouse populations associated with aerial baiting of cereal crop paddocks and reported population density reductions ranging between $56 \%$ and $94 \%$ in trial sites in north western Victoria compared with a $20 \%$ reduction in populations on the unbaited Control sites. Studies by Mutze and Sinclair (2004) found that $\mathrm{ZnP}$ could reduce mouse population by $>90 \%$ when used either five days before sowing or six weeks after sowing cereal crops. In contrast, when baiting occurred only two days after sowing, mouse numbers were reduced by only $30 \%$ and obvious mouse diggings were abundant along the seed rows. Caughley et al. (1998b) reported mortality rates ranging from 95\% down to slight population increases associated with $\mathrm{ZnP}$ baiting control operations in Queensland cereal/sorghum/soybean crops at various stages of the crop cycle. The least successful kills occurred when stubble was baited immediately following harvest when presumably spilled grain was abundant on the ground (Caughley et al. 1998a; Caughley et al. 1998b). In separate study in wheat paddocks, we have measured spilled grain on the ground in the months following wheat harvest at up to150 $\mathrm{kg} / \mathrm{ha}$ ( $\mathrm{n}=4$ paddocks, Ruscoe et al. unpublished data). In a laboratory trial, wild house mice ate more toxic wheat grain and mortality rate was significantly higher $(85 \%)$ in the presence of a less-favoured alternative grain (lentils), compared to mortality rates of $47 \%$ and $53 \%$ in the presence of a more-favoured cereal grain (wheat and barley, respectively) (Henry et al. 2021). These studies all suggest that alternative food availability could be reducing the bait consumption by mice leading to reduced kill rates if a single toxic grain is not lethal.

The paddocks in which we conducted our trials were recently emerged canola and wheat crops in early autumn. We trapped very few younger animals, and no pregnant/lactating females or scrotal males were observed, indicating that the summer breeding probably finished in March (early autumn) 2021. Estimates of mouse population size from the capture-mark-recapture analyses revealed Pre-treatment mouse numbers between 300-500 mice per ha which is high, but not as high as estimated during other plagues. Prior to sowing, farmers had burned the (previous year) crop-stubble to reduce food and cover available to mice. In this respect, the paddock-scape had virtually all background food removed and 
resembled the paddocks of 30 years ago before conservation agriculture became prominent. As such, there was not much else on the ground, and the mice should have readily found toxic grains. We calculated the percentage population reduction on each site using trap success (for comparison with previous studies): $\mathrm{ZnP25}$ showed similarly variable reductions (64-92\%) in population size as in previous studies (Brown et al. 2002; Mutze and Sinclair 2004) while the ZnP50 showed 89-97\% reductions. It is concerning that our $\mathrm{ZnP} 25$ treated sites showed large variability in population reductions as varying levels of background food would not have been a contributing factor in this, as has been suggested previously. The effect of higher levels of background food availability associated with the more recent changes to conservation agricultural practices (that include leaving standing stubble and chaff that provides cover habitat for mice and ploughing which buries residual grain) on toxic grain uptake, requires in-field evaluation.

Longevity of $\mathrm{ZnP}$ baits may vary depending on the environmental factors where the baits are applied, whether the baits are pellets or whole grain, and time since deployment. $\mathrm{ZnP}$ degradation has been shown to increase under higher rainfall and humidity levels (Hilton and Robison 1972; Sterner and Mauldin 1995; Twigg et al. 2001). Twigg et al. (2001) demonstrated a reduction of $\mathrm{ZnP}$ on whole-wheat bait under seasonal wet conditions compared to dry conditions, but the available bait was considered lethal to rats for 8-14 days under either condition. Variability in baiting success was also found in Hawaii, where the effectiveness of $\mathrm{ZnP}$ on both pelleted bait and oat grain bait (groats) was tested against pest rats (Rattus rattus, $R$. norvegicus and R. exulans) (Sugihara et al. 1995). Post-baiting captures of all rat species did not differ between the ZnP Treatments and the untreated Controls and the authors concluded that $\mathrm{ZnP}$ was not effective in reducing the pest populations, particularly of $R$. norvegicus, which may have in part been due to rain during the trial. In contrast Bell (1972) found that ZnP loss from baits occurred over time but that it was some factor or factors other than temperature and precipitation were responsible for the deterioration of the bait's toxicity. While exposure to weather hastens the chemical decomposition of the $\mathrm{ZnP}$ particularly in the first week post-deployment, some deterioration, albeit at a slower rate, occurred when bait was stored in the opened original bags at room temperatures.

In our study we had three fine nights following the application of the baiting treatments followed by two nights of modest rain (15 and $22 \mathrm{~mm}$ per night) during the Post-treatment trapping. There should have been sufficient time for animals to encounter baits before any degradation occurred if indeed it did in the eight days post baiting that we surveyed.

Without background food availability and wet weather affecting bait take, we conclude that, as found in the laboratory trials of Henry et al. (2021) and Hinds et al. (2021) the ZnP25 formulated bait containing on average $1 \mathrm{mg} \mathrm{ZnP}$ was not sufficient to kill mice unless they found and consumed multiple baits before starting to feel sick. Any animal that only found and ate one grain of $\mathrm{ZnP} 25$ probably consumed a sublethal dose and become averse to the baits likely refusing to take more (Henry et al. 2021). Such 
aversion can last for 20-30 days (Parker and Hannan-Jones 1996) and has been reported in other rodents (Shepherd and Inglis 1993). This highlights the importance of each grain delivering an adequate dose to kill each mouse. The $\mathrm{ZnP50}$ bait grains contained on average $2 \mathrm{mg}$ of $\mathrm{ZnP}$ each which for a $15 \mathrm{~g}$ mouse should deliver a toxic dosage equivalent to the newly derived $\mathrm{LD}_{90}$ (Hinds et al. 2021).

The average weight of mice in our study was $13.2 \mathrm{~g}$ (range: $6.5-24 \mathrm{~g}$ ). According to Hinds et al. (2021), $13 \mathrm{~g}$ mice would need to ingest at least $1.4 \mathrm{mg} \mathrm{ZnP}$ to receive a lethal dose ( $\left.\mathrm{LD}_{90}\right)$. There is some variability in the amount of toxin on individual grains as a result of the manufacturing process. From the grain samples that we had independently analysed, $50 \%$ of ZnP25 grain samples contained $\geq 1.0 \mathrm{mg}$ $\mathrm{ZnP}$ but only 4 of 30 (13\%) of the grains had $\geq 1.4 \mathrm{mg}$. This means that $87 \%$ of $\mathrm{ZnP} 25$ grains available to be consumed (at $1 \mathrm{~kg} / \mathrm{ha}$ ) contained a sub lethal dose for the average mouse, and if eaten in isolation would likely result in bait aversion. In contrast, $77 \%$ of $\mathrm{ZnP} 50$ grains contained $\geq 1.4 \mathrm{mg} \mathrm{ZnP}$ reducing the probability of sublethal dose-related aversion. In competition for a mouse's attention while foraging is spilled grain, (plus weed seeds and invertebrates) in paddocks.

The best evaluation of pest animal control effectiveness is the reduction in damage. This, however, can be difficult to assess because counts of seedlings need to be measured several weeks after emergence, by which time the damage is done, and re-baiting is ineffectual. Here we report the treatment efficacy based on the change in population size of the target pest population. Efficacy should incorporate cost and benefit analysis of the treatment (management and crop loss data) as well as humaneness and hazards to non-target animals. The benefit of using one bait formulation over the other must include cost considerations. The process for making and delivering the alternative $\mathrm{ZnP}$ baits used in this study is the same, the only cost difference is in the additional quantity of base $\mathrm{ZnP}$ technical powder which is about $\$ 1 / \mathrm{kg}$ of bait (A. Shilling, pers comm.).

In southern cropping regions of Australia, most damage to crops occurs at sowing when mouse abundance is high at the end of the breeding season. The best option for bait application remains to bait at sowing or shortly before to protect crops at this critical time, and when alternative food is likely to be at a nadir. Given the time constraints involved, it is imperative to bait only once and with a bait that gives the best chance of a successful outcome. This study demonstrates the far higher certainty of achieving a high kill rate with the new ZnP50 bait compared to the currently registered formulation hopefully negating the need for repeat baiting.

Acknowledgements: We sincerely thank the farmers for allowing us to undertake this experiment on their properties. We thank Leigh Nelson and Ken Young and Leigh Nelson (GRDC) for ongoing support. We are also grateful for logistical and field support from NSW Department of Primary Industries (Dave Forsyth, Stephen Jackson, Emma Sawyers, Pat Taggart). Peter Caley (Data61, CSIRO) reviewed our R code, analysis, and the draft manuscript. 
393 Author contribution: WAR, PRB, LAH and SH designed this research. All authors (except RPD)

394 collected experimental field data. WAR and RPD analysed the data. WAR, RPD and PRB wrote the 395 first draft manuscript. All authors contributed to the final manuscript.

Ethics Approval: This study was approved by the CSIRO Wildlife and Large Animal, Animal Ethics Committee (approval number: 2019-18) and adheres to the 8th Edition of the Australian Code and Use of Animals for Scientific Purposes. This article does not contain any studies with human participants performed by any of the authors.

401

Availability of data and material: Data are held by the Commonwealth Science and Industry Research

Organisation (CSIRO), Australia, and will be made available upon reasonable request to the senior author.

405

\section{Supplementary information: Supplementary material.docx}

Declaration of Funding: This study was funded by the Grains Research and Development Corporation (CSP1804-012RTX and CSP1806-015RTX) and supported by CSIRO Health \& Biosecurity.

\section{References}

APVMA (2000) Evaluation of the new active zinc phosphide in the product MouseOff zinc phosphide bait. https://apvma.gov.au/node/14101. National Registration Authority for Agricultural and Veterinary Chemicals. (Canberra, Australia)

Bell HB (1972) The hazards of secondary poisoning from zinc phosphide to selected vertebrate species. (University of Tennessee.

Brown PR, Chambers LK, and Singleton GR (2002) Pre-sowing control of house mice (Mus domesticus) using zinc phosphide efficacy and potential non-target effects. Wildlife Research 29, 27 37. strychnine for control of populations of wild house mice Mus domesticus in Victoria. Wildlife Research 24, 159-172. doi: https://doi.org/10.1071/WR96018.

Caughley J, Bomford M, Parker B, Sinclair R, Griffiths J, and Kelly D (1998a) 'Managing vertebrate pests: rodents.' (Bureau of Resource Sciences and Grains Research Development Corporation: Canberra) 
Caughley J, Donkin C, and Strong K Managing mouse plagues in rural Australia. 1998b, University of Nebraska - Lincoln. (Ed. R Baker and A Crabb) pp. 160 - 165. (University of California, Davis.)

Caughley J, Monamy V, and Heiden K (1994) Impact of the 1993 Mouse Plague. GRDC. (Canberra, Australia.)

Chambers LK, Singleton GR, and Krebs CJ (2000) Movements and social organization of wild house mice (Mus domesticus) in the wheatlands of northwestern Victoria, Australia. Journal of Mammology 81, 59-69.

Chapman A (1981) Habitat preference and reproduction of feral house mice, Mus musculus, during plague and non-plague situations in Western Australia. Wildlife Research 8, 567-579. doi: https://doi.org/10.1071/WR9810567.

Gelman A and Rubin DB (1992) Inference from iterative simulation using multiple sequences. Statistical Science 7, 457-472, 416.

Guale FG, Stair EL, Johnson BW, Edwards WC, and Haliburton JC (1994) Laboratory diagnosis of zinc phosphide poisoning. Vet Hum Toxicol 36, 517-519.

Henry S, Brown PR, Van de Weyer N, Robinson F, and Hinds LA (2021) Effects of background food on alternative grain uptake and zinc phosphide efficacy in wild house mice. Pest Management Science, https://doi.org/10.1002/ps.6720.

Hilton HW and Robison WH (1972) Fate of zinc phosphide and phosphine in the soil-water environment. Journal of Agricultural and Food Chemistry 20, 1209-1213. doi: 10.1021/jf60184a056.

Hinds LA, Henry S, Sharma S, Leung L, Dyer C, and Mayer L (2014) Effects or oral uptake of the chemosterilant 4-vinylcyclohexene diepoxide in wild house mice, Mus domesticus. . In '26th Vertebrate Pest Control Conference'. (Ed. RM Timm and JM O'Brien) pp. 380 - 385.: University of California, Davis)

Hinds LA, Henry S, Van de Weyer N, Robinson F, Ruscoe WA, and Brown PR (2021) Acute oral toxicity of zinc phosphide: an assessment for wild house mice in Australia. bioRxiv, 2021.2012.2009.472031. doi: 10.1101/2021.12.09.472031.

Kellner K (2015) jagsUI: a wrapper around rjags to streamline JAGS analyses. R package version 1, 2015.

Krebs CJ, Kenney AJ, and Singleton GR (1995) Movements of feral house mice in agricultural landscapes. Australian Journal of Zoology 43, 293-302.

Lohr MT and Davis RA (2018) Anticoagulant rodenticide use, non-target impacts and regulation: A case study from Australia. Sci Total Environ 634, 1372-1384. doi: 10.1016/j.scitotenv.2018.04.069.

McLeod L and Saunders G (2013) Pestcides used in the management of vertebrate pests in Australia: a review. NSW Department of Primary Industries. (Orange, NSW) 
Mutze G (1993) Cost-effectiveness of poison bait trails for control of house mice in mallee cereal crops. Wildlife Research 20, 445 - 455. doi: https://doi.org/10.1071/WR9930445.

Mutze G and Sinclair R (2004) Efficacy of zinc phosphide, strychnine and chlorpyrifos as rodenticides for the control of house mice in South Australian cereal crops. Wildlife Research 31, 249-257.

Mutze GJ (1989) Mouse plagues in South Australian cereal-growing areas .1. Occurrence and distribution of plagues from 1900 to 1984. Wildlife Research 16, 677-683. doi:

https://doi.org/10.1071/WR9890677.

Parker RW and Hannan-Jones M (1996) The potential of zinc phosphide for mouse plague control in Australia. (QDoNRa Mines: Brisbane)

Plummer M JAGS: A program for analysis of Bayesian graphical models using Gibbs sampling. 2003 pp. 1-10. (Vienna, Austria.)

Pople A, Scanlan J, Cremasco P, and Farrell J (2013) Population dynamics of house mice in Queensland grain-growing areas. Wildlife Research 40, 661-674. doi:

https://doi.org/10.1071/WR13154.

R Core Team (2020) R: A language and environment for statistical computing. (R Foundation for Statistical Computing: Vienna, Austria. URL https://www.R-project.org/.)

Royle JA, Nichols JD, Karanth KU, and Gopalaswamy AM (2009) A hierarchical model for estimating density in camera-trap studies. Journal of Applied Ecology 46, 118-127. doi: https://doi.org/10.1111/j.1365-2664.2008.01578.x.

Ruscoe WA, Brown PR, Henry S, Van de Weyer N, Robinson F, Hinds LA, and Singleton GR (2022) Conservation agriculture practices have changed habitat use by rodent pests: implications for management of feral house mice. Journal of Pest Science 95, 493 - 503. doi: https://doi.org/10.1007/s10340-021-01370-7.

Saunders GR and Giles JR (1977) A relationship between plagues of the house mouse, Mus musculus (Rodentia : Muridae) and prolonged periods of dry weather in south-eastern Australia. Wildlife Research 4, 241-247. doi: https://doi.org/10.1071/WR9770241.

Shepherd DS and Inglis IR (1993) Toxic Bait Aversions in Different Rat Strains Exposed to an Acute Rodenticide. The Journal of wildlife management 57, 640-647. doi: 10.2307/3809294.

Singleton GR, Brown PR, Pech RP, Jacob J, Mutze GJ, and Krebs CJ (2005) One hundred years of eruptions of house mice in Australia - a natural biological curio. Biological journal of the Linnean Society 84, 617-627. doi: 10.1111/j.1095-8312.2005.00458.x.

Staples L, Smith M, Pontin K, and Hunt W Use of zinc phosphide to overcome rodent infestations. 2003, Canberra, ACT Australia. (Ed. EJ Wright, MC Webb, and E Highley) pp. 110 - 115. (CSIRO Stored Grain Research Laboratory) 
Sterner RT and Mauldin RE (1995) Regressors of whole-carcass zinc phosphide/phosphine residues in voles: indirect evidence of low hazards to predators and/scavengers. Archives of Environmental Contamination and Toxicology 28, 519 - 523.

Sugihara RT, Tobin ME, and Koehler AE (1995) Zinc phosphide baits and prebaiting for controlling rats in Hawaiian sugarcane. The Journal of wildlife management 59, 882 - 889.

Tickes BR (1985) Zinc phosphide in subterranean burrow systems. Bulletin of Environmental Contamination and Toxicology 34, 557-559.

537

538

539

540

541

542

543

544

545

546

Tkadlec E and Rychnovsky B (1990) Residues of $\mathrm{Zn}_{3} \mathrm{P}_{2}$ in the common vole (Microtus arvalis) and secondary poisoning hazards to predators. Folia Zoologica 39, 147 - 156.

Twigg LE, Martin GR, Wilson N, Goddard D, Watkins R, and Armstrong PJ (2001) Longevity of zinc phosphide on wheat bait in tropical Australia. Wildlife Research 28, 261-267. doi:

https://doi.org/10.1071/WR00062. 
550 Table 1. The numbers of individual mice trapped on each site, the estimated population size based on

551 CMR estimates ( \pm se), and the trap success $(\%)$ for each survey (Pre- and Post- treatment), and the 552 percent change in estimated population size Pre- to Post-treatment (\% Change).

553

\begin{tabular}{|c|c|c|c|c|c|c|c|c|c|c|}
\hline \multirow[t]{2}{*}{ Treatment } & \multirow[t]{2}{*}{ Site $^{\#}$} & \multicolumn{3}{|c|}{$\begin{array}{l}\text { Number Individuals caught* (no. } \\
\text { re-trapped from Pre- survey) }\end{array}$} & \multicolumn{3}{|c|}{$\begin{array}{l}\text { CMR population estimate } \\
\qquad\left(\text { mice } \mathrm{ha}^{-1}\right)\end{array}$} & \multicolumn{3}{|c|}{$\begin{array}{c}\text { Trap Success } \$ \\
(\%)\end{array}$} \\
\hline & & Pre- & Post- & $\%$ Change & Pre- & Post- & \%Change & Pre- & Post- & \%Change \\
\hline \multirow[t]{3}{*}{ Control } & $\mathrm{RN}^{1}$ & 144 & $63(15)$ & -56.1 & $292 \pm 12.2$ & $139 \pm 5.3$ & -52.2 & 108 & 56 & -48 \\
\hline & Rss & 99 & $49(8)$ & -50.7 & $202 \pm 10.0$ & $106 \pm 4.5$ & -47.0 & 65 & 41 & -37 \\
\hline & Dam & 103 & $97(10)$ & -6.0 & $209 \pm 10.2$ & $213 \pm 6.6$ & +1.1 & 67 & 87 & +29 \\
\hline \multirow[t]{3}{*}{ ZnP50 } & $\mathrm{RS}^{1}$ & 210 & $10(0)$ & -95.4 & $427 \pm 15.2$ & $20 \pm 2.0$ & -95.1 & 110 & 4 & -97 \\
\hline & GS & 116 & $16(0)$ & -86.2 & $236 \pm 10.9$ & $34 \pm 2.7$ & -85.2 & 66 & 7 & -89 \\
\hline & BW & 152 & $6(0)$ & -95.8 & $309 \pm 12.7$ & $14 \pm 1.6$ & -95.5 & 97 & 3 & -97 \\
\hline \multirow[t]{3}{*}{$\mathrm{ZnP} 25$} & $\mathrm{BR}^{1}$ & 245 & $18(0)$ & -92.8 & $497 \pm 16.3$ & $37 \pm 2.7$ & -92.3 & 126 & 10 & -92 \\
\hline & GR & 94 & $22(0)$ & -77.3 & $191 \pm 9.8$ & $47 \pm 3.0$ & -75.3 & 57 & 11 & -81 \\
\hline & BE & 98 & $32(1)$ & -67.3 & $198 \pm 10.0$ & $69 \pm 3.8$ & -64.8 & 69 & 24 & -64 \\
\hline
\end{tabular}

$554 *$ Data: $80 \%$ of the total number of individuals for 5 nights used from the Post-treatment survey for comparison between the 555 Pre- (4 nights) and Post- (5 nights) treatment surveys.

$556 \$$ Trap Success is the number of animals caught per 100 trap nights. This can be more than 100 when multiple animals are 557 caught in one trap. An animal can be caught on multiple nights.

$558 \quad$ \# Sites marked with ${ }^{1}$ are from Block 1, the remainder from Block 2. 
561 Fig. 1. Population densities ( $\pm 95 \%$ Credible Intervals) estimated from CMR data (see Supp. Materials

562 1) for each of the nine sites (Block 1, dashed lines; Block 2, solid lines) for the Pre- and Post- treatment 563 trapping surveys separated into the Treatments (Control, ZnP25, ZnP50).

565 Fig. 2. Histograms of the posterior distribution of treatment efficacy (the proportional reduction in 566 mouse population size relative to Control sites) associated with using: (a) ZnP25 bait and (b) ZnP50 567 bait. Filled circles show the median percent reduction in population size, thick lines the $50 \%$ and thin 568 lines the $95 \%$ credible intervals.

569

570 Fig. 3. The probably of achieving a certain reduction in population size or better using the ZnP50 bait 571 (solid black line) and the ZnP25 bait (solid grey line). The dotted vertical line reveals there is a $90 \%$ 572 chance of getting a greater than $80 \%$ reduction in population size using ZnP50 but only a $20 \%$ chance 573 of achieving that outcome using $\mathrm{ZnP} 25$.

574

575 
577 Figure 1

578
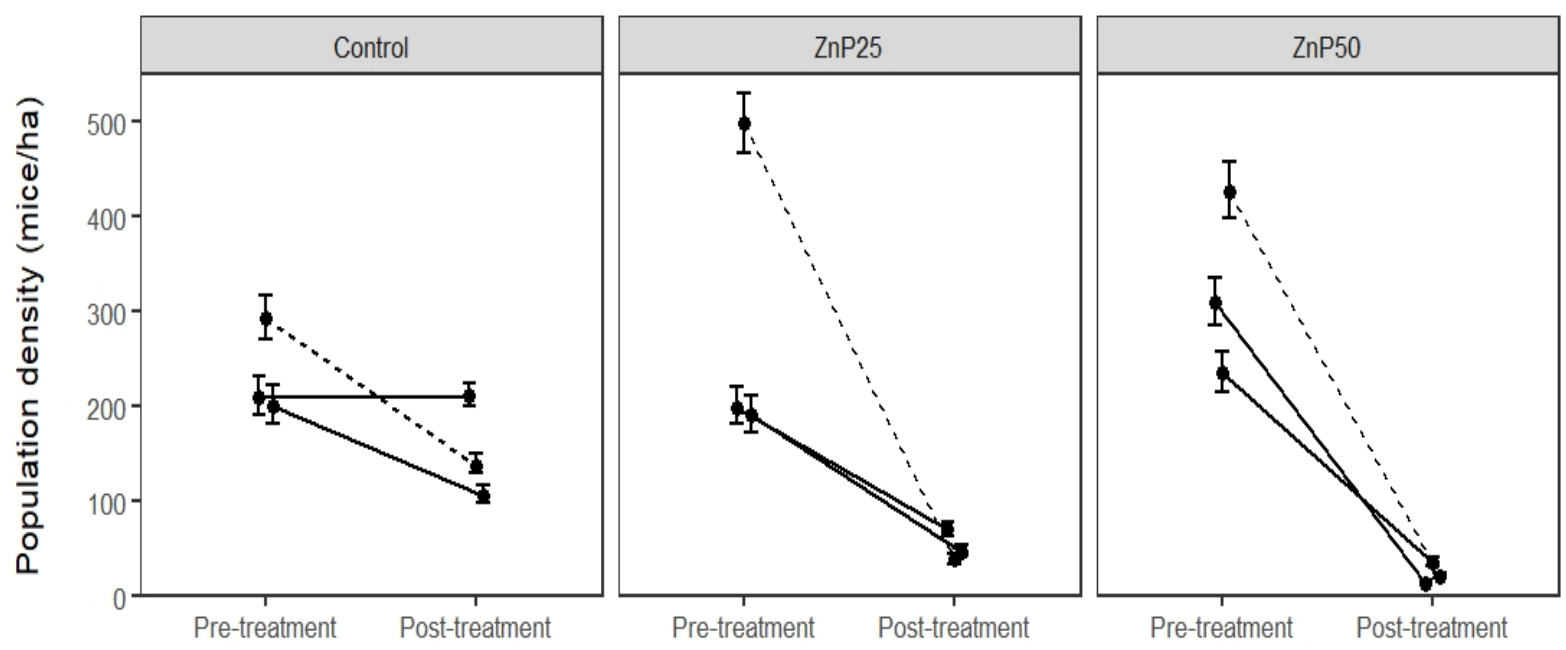

579

580

581

582 
a) ZnP25

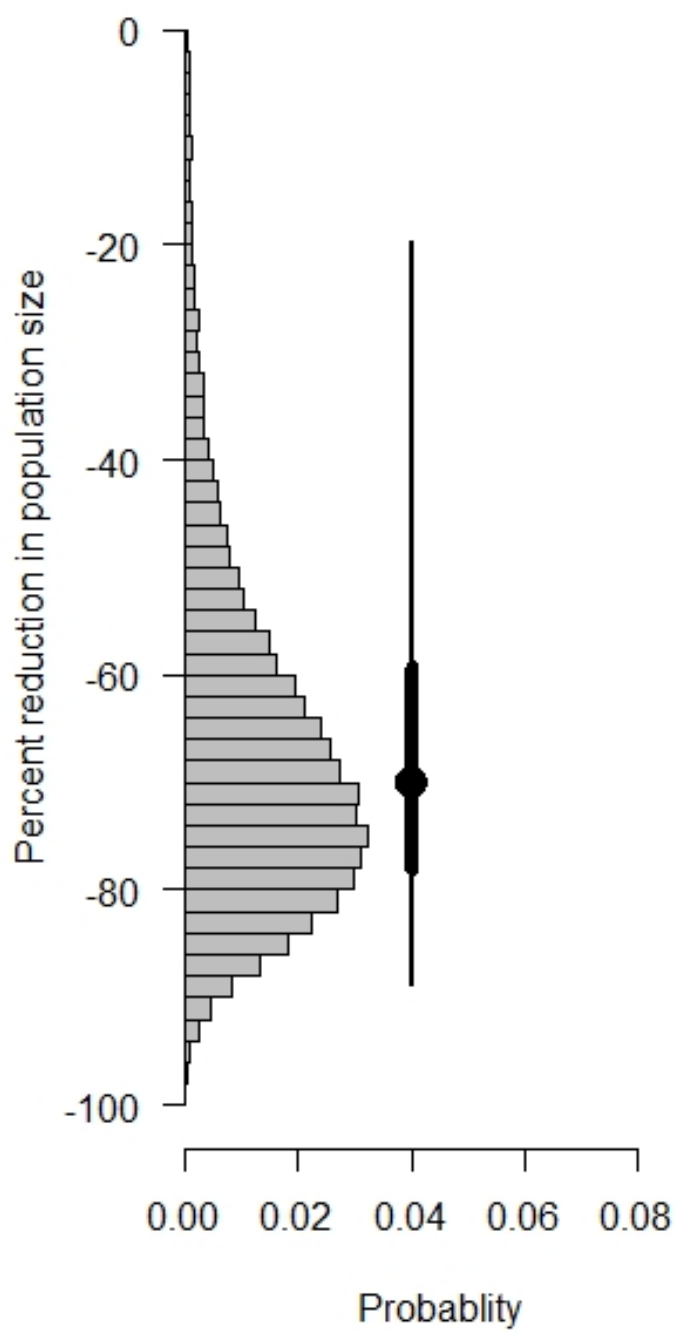

585

586 b) ZnP50

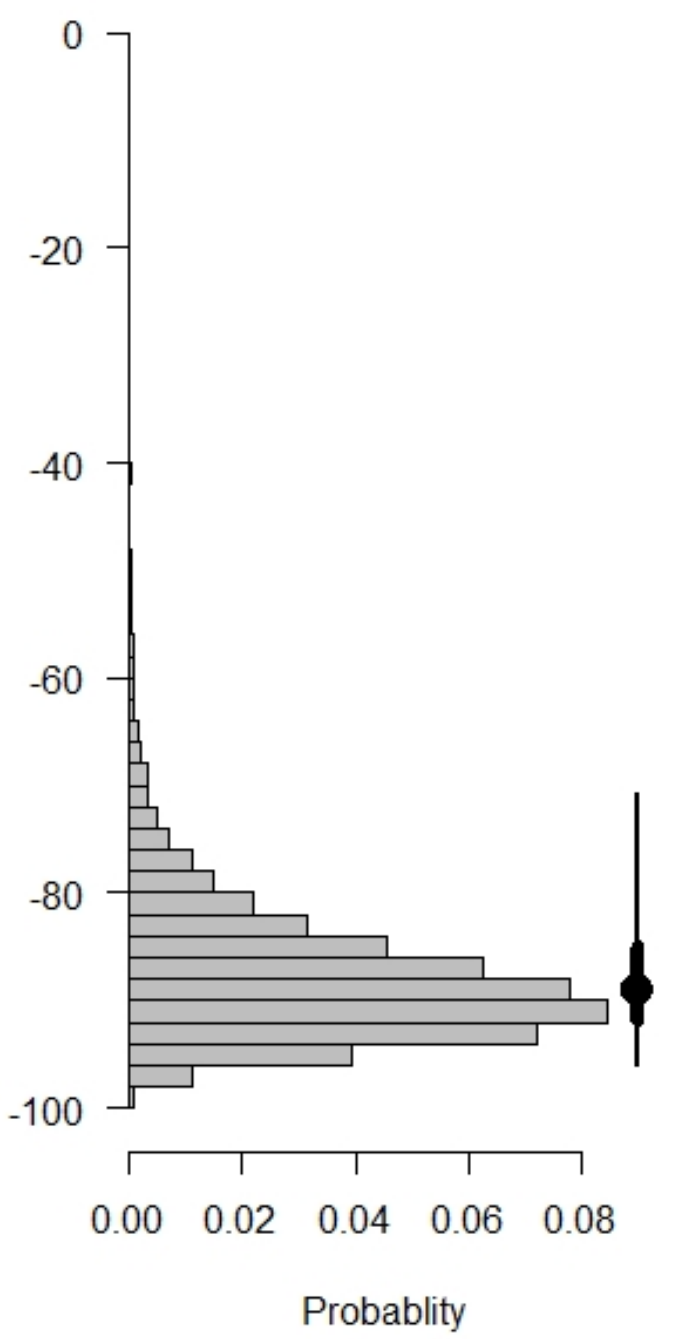


$587 \quad$ Figure 3

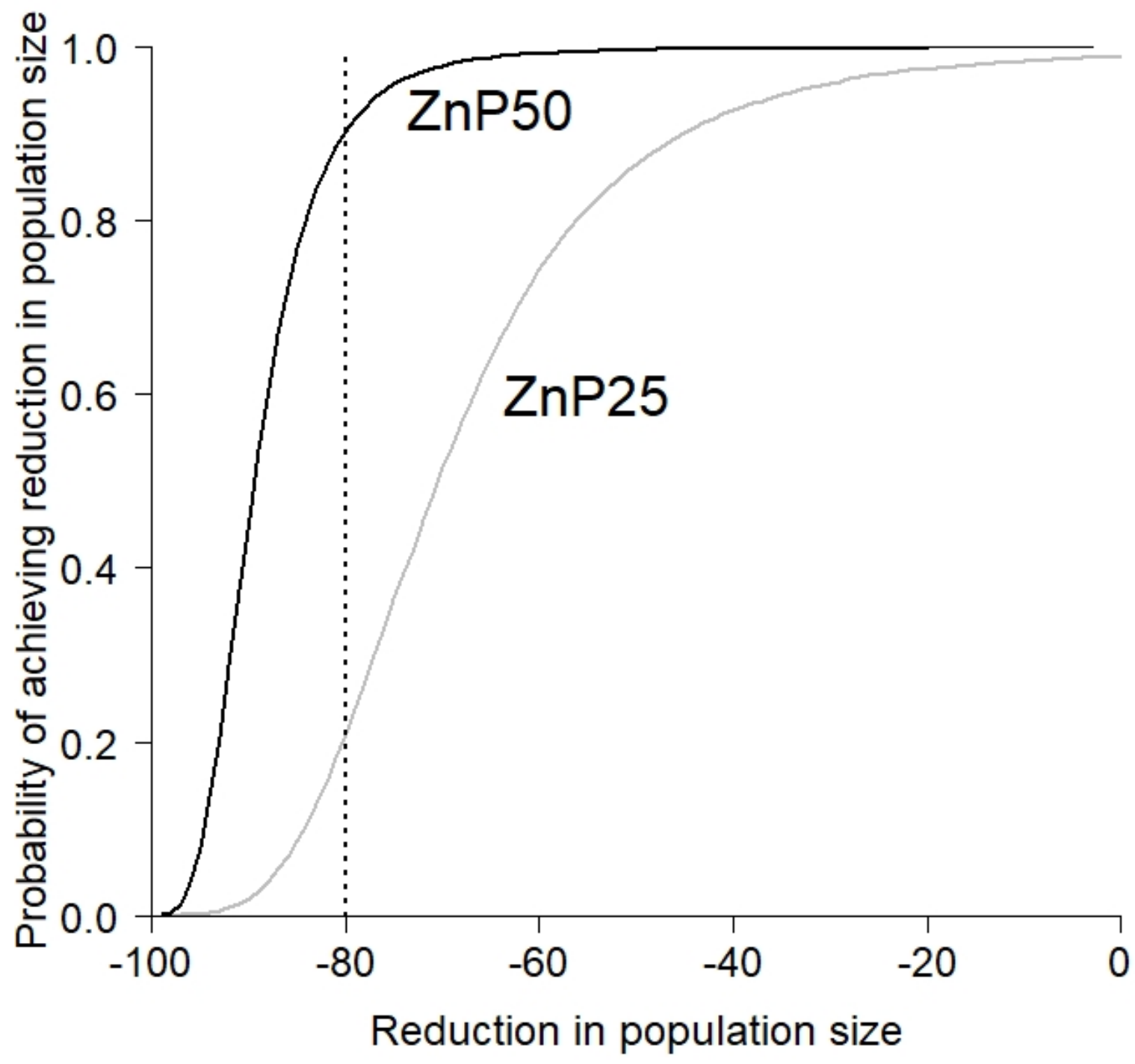

